\title{
PENINGKATAN HASIL BELAJAR SIFAT-SIFAT PENGERJAAN HITUNG BILANGAN BULAT MELALUI MODEL PEMBELAJARAN KOOPERATIF TIPE TPS (THINK PAIR SHARE)
}

\author{
Napi'ah \\ Guru SDN Puri Kec. Puri Kabupaten Mojokerto \\ Email: napiah17101962@gmail.com
}

\begin{abstract}
AbstrackThis study was conducted at the first semester at fifth grade student of SDN PURI Mojokerto in Academic Year 2013-2014. This study uses classroom action research consists of two cycles. The objects of this study as much as 23 students. The data in this study were analyzed using descriptive analysis in order to describe the teacher's activities, the student's activities and student's learning outcomes in learning. The results of this study showed the average of learning outcomes in the second cycle increased from the first cycle in the amount of 84,57 with the classical completeness $73,91 \%$. Thus model implementaion of cooperative learning type TPS (Think Pair Share) can increase the teacher's activities, student's activities and learning outcomes of fifth grade students of SDN PURI Mojokerto in Academic Year 2013-2014.
\end{abstract}

Key words : learning outcomes, integer, think pair share

Kemajuan bangsa Indonesia dapat dicapai melalui penataan pendidikan yang baik, dengan adanya berbagai upaya peningkatan mutu pendidikan diharapkan dapat menaikkan harkat dan martabat manusia. Untuk mencapainya, pembaharuan pendidikan di Indonesia perlu terus dilakukan untuk menciptakan dunia pendidikan yang adaptif terhadap perubahan zaman. Berbagai upaya yang telah ditempuh untuk meningkatkan kualitas pembelajaran, antara lain : pembaharuan dalam kurikulum, pengembangan model pembelajaran, perubahan sistem penilaian, dan lain sebagainya. Salah satu unsur yang sering dikaji dalam hubungannya dengan prestasi belajar adalah model yang digunakan tenaga pendidik dalam kegiatan pembelajaran di sekolah. Selama ini kegiatan pembelajaran yang berlangsung di dalam kelas berpusat kepada guru, sehingga siswa cenderung kurang aktif.

Di dalam Undang - Undang Republik Indonesia No.20 tahun 2003 tentang Sistem Pendidikan Nasional, menyebutkan " Pendidikan adalah usaha sadar dan terencana untuk mewujudkan suasana belajar dan proses pembelajaran agar peserta didik secara aktif mengembangkan potensi dirinya untuk memiliki kekuatan spiritual keagamaan, pengendalian diri, kepribadian, kecerdasan, akhlak mulia, serta keterampilan yang dibutuhkan bagi dirinya, masyarakat, bangsa dan negara".Proses pembelajaran matematika di sekolah saat ini kurang meningkatkan aktivitas belajar siswa, terutama dalam pembelajaran matematika. Masih banyak tenaga pendidik yang menggunakan metode konvensional secara monoton dalam

43 BRILIANT: Jurnal Riset dan Konseptual

Volume 1 Nomor 1, November 2016 
kegiatan pembelajaran di kelas, sehingga suasana belajar terkesan kaku dan didominasi oleh guru. Pada pembelajaran konvensional belajar hanya berdasarkan perintah dan tugas-tugas yang diberikan guru, kondisi ini tidak akan menumbuhkembangkan kemampuan diri, kreatifitas, dan motivasi siswa untuk menyukai, mempelajari dan memahami matematika (Trianto, 2011:57).

Oleh karena itu perlu dikembangkan pembelajaran kooperatif.Pembelajaran kooperatif adalah pembelajaran yang mengharuskan siswa untuk bekerja dalam suatu tim untuk menyelesaikan masalah, menyelesaikan tugas, atau mengerjakan sesuatu untuk tujuan bersama (Amiyah, Murtadlo, 2011:98). Dari uraian di atas tentang pembelajaran kooperatif peneliti memilih model pembelajaran kooperatif tipe TPS (Think Pair Share).Ada tiga langkah dalam model ini, antara lain : berfikir (Thinking) yaituguru mengajukan pertanyaan atau issu yang terkait dengan pelajaran dan siswa diberi waktu satu menit untuk berpikir sendiri mengenai jawaban atau issu tersebut, berpasangan (Pairing) yaitu guru meminta kepada siswa untuk berpasangan dan mendiskusikan mengenai apa yang telah dipikirkan, dan berbagi (Sharing) yaitu guru meminta pasangan-pasangan tersebut untuk berbagi atau bekerja sama dengan kelas secara keseluruhan mengenai apa yang telah mereka bicarakan (Amiyah, Murtadlo, 2011:111).

Berdasarkan latar belakang yang telah diuraikan di atas, maka rumusan masalah penelitian ini adalah (1) Bagaimanakah aktivitas guru dalam mengelola kelas dengan menerapkan model pembelajaran kooperatif tipe TPS(Think Pair Share) pada siswa kelas V SDN PURI Mojokerto pada materi pokok sifat-sifat pengerjaan hitung pada bilangan bulat? (2) Bagaimanakah aktivitas siswa dalam penerapan model pembelajaran kooperatif tipe TPS (Think Pair Share) pada siswa kelas V SDN PURI Mojokerto pada materi pokok sifat-sifat pengerjaan hitung pada bilangan bulat ? (2) Apakah model pembelajaran kooperatif tipe TPS(Think Pair Share) dapat meningkatkan hasil belajar matematika siswa pada materi pokok sifat-sifat pengerjaan hitung pada bilangan bulat kelas V SDN PURI Mojokerto?

Adapun tujuan penelitian yang ingin dicapai penulis dalam penelitian ini adalah: (1) Untuk mengetahui aktivitas guru dalam mengelola kelas pada siswa kelas V SDN PURI Mojokerto pada materi pokok sifat-sifat pengerjaan hitung pada bilangan bulat dengan menerapkan model pembelajaran kooperatif tipe TPS(Think Pair Share). (2) Untuk mengetahui aktivitas siswa pada siswa kelas V SDN PURI Mojokerto pada materi pokok sifat-sifat pengerjaan hitung pada bilangan bulat dalam penerapan model pembelajaran kooperatif tipe TPS(Think Pair Share). (3) Untuk mengetahui peningkatan hasil belajar siswa kelas V SDN PURI Mojokerto terhadap pelajaran matematika pada materi pokok sifat-sifat pengerjaan hitung pada bilangan bulat setelah diterapkan model pembelajaran kooperatif tipe TPS(Think Pair Share). 


\section{METODE \\ Rancangan Penelitian}

Penelitian ini merupakan Penelitian Tindakan Kelas (PTK) (Arikunto,2006:91). Dalam penelitian ini peneliti mengidentifikasikan variabelvariabel penelitian yaitu : (1) Variabel bebas (independent). Indikator: model pembelajaran kooperatif tipe TPS(Think Pair Share). Variabel bebas (independent) adalah variabel yang mempengaruhi variabel lain (Arikunto, 2006:119). Variabel bebas yang dimaksud dalam peneliti adalah model pembelajaran kooperatif tipe TPS(Think Pair Share). (2) Variabel terikat (dependent).

Indikator: hasil belajar matematika. Variabel terikat (dependent) adalah variabel yang dipengaruhi variabel lain (Arikunto, 2006:119). Variabel terikat dalam penelitian ini adalah hasil belajar siswa.

Pada penelitian ini variabelnya, yaitu aktivitas guru, aktivitas siswa dan hasil belajar matematika siswa. Penelitian ini dilaksanakan dalam 2 kali siklus.Prosedur Penelitian Tindakan Kelas (PTK) dimulai dengan siklus pertama yang terdiri dari empat kegiatan, yaitu, perencanaan (planning), pelaksanaan (acting), pengamatan (observing), dan refleksi (reflecting). Berdasarkan hal tersebut, maka peneliti menggunakan jenis penelitian kualitatif dengan pendekatan deskriptif. Sebagaimana pendapat Sugiono (2012:8) yang menyatakan, bahwa penelitian "kualitatif dilakukan pada objek yang berkembang apa adanya, tidak dimanipulasi oleh peneliti, dan kehadiran peneliti tidak mempengaruhi dinamika pada objek tersebut".

Penelitian ini menggunakan metode kualitatif dengan pendekatan deskriptif guna menjelaskan keadaan sebenarnya di lapangan, sehingga peneliti lebih mudah dalam mendeskripsikan fakta-fakta yang ada di lapangan.

\section{Subjek Penelitian}

Penelitian ini dilakukan di SDN PURI Mojokerto pada semester I tahun pelajaran 2013/2014. Adapun subjek penelitian ini adalah siswa-siswi kelas V dengan jumlah siswa sebanyak 23 siswa. Pengambilan sampel didasarkan pada tujuan penelitian yaitu untuk meningkatkan hasil belajar matematika siswa kelas V SDN PURI Mojokerto dengan penerapan model pembelajaran kooperatif tipe TPS(Think Pair Share).

\section{Metode Pengumpulan Data}

Metode pengumpulan data adalah cara yang digunakan peneliti dalam mengumpulkan data penelitiannya (Arikunto, 2006:149). Dalam penelitian ini metode pengumpulan data yang digunakan adalah metode observasi dan metode tes.

\section{Pengembangan Instrumen Pengumpulan Data}

Instrumen penelitian adalah alat atau fasilitas yang digunakan oleh peneliti dalam mengumpulkan data agar pekerjaannya lebih mudah dan hasilnya lebih baik, dalam arti lebih cermat, lengkap, dan sistematis sehingga lebih mudah 
diolah (Arikunto, 2006:149). Dalam penelitian ini instrumen penelitian yang digunakan adalah lembar observasi hasil belajar siswa dan lembar tes. Lembar Observasi Kegiatan Belajar Mengajar. Lembar observasi pengolahan model pembelajaran kooperatif tipe TPS (Think Pair Share). Lembar observasi aktivitas siswa. Lembar Tes Soal.

\section{Teknik Analisis Data}

Analisis data adalah cara yang paling menentukan dalam menyusun dan mengolah data yang terkumpul sehingga dapat menghasilkan suatu kesimpulan yang dapat dipertanggungjawabkan. Pada penelitian ini digunakan teknik analisis deskriptif kualitatif yaitu suatu metode penelitian yang bersifat menggambarkan kenyataan atau fakta sesuai dengan data yang diperoleh dengan tujuan untuk mengetahui hasil belajar yang dicapai siswa terhadap kegiatan pembelajaran serta aktivitas siswa selama proses pembelajaran.

\section{Analisis Data Pengelolaan Pembelajaran.}

Data hasil pengamatan guru dalam mengelola pembelajaran dianalisis dengan mengggunakan rata-rata skor, yaitu: rata - rata $=$ jumalah nilai yang diperoleh dibagi jumlah aspek yang diamati.

\section{Analisis Data Aktivitas Siswa.}

Analisis data berupa pengamatan yang diperoleh dari instrument lembar pengamatan pengelolaan pembelajaran di kelas dengan aktivitas belajar siswa menggunakan rata-rata, yaitu: jumlah skor keseluruhan dibagi jumlah siswa.

\section{Analisis Data Kemampuan Belajar}

Ketuntasan hasil belajar siswa dapat diukur dengan menggunakan tes setelah tindakan. Siswa dikatakan tuntas secara individu jika terpenuhinya KKM yang telah ditetapkan oleh sekolahnya, tetapi jika siswa belum mencapai KKM yang telah ditetapkan maka siswa tersebut belum tuntas.

Untuk mengetahui pencapaian ketuntasan hasil belajar siswa, maka data berupa nilai yang diperoleh dengan mengadakan tes tiap siklus akan dianalisis dengan batas ketuntasan siswa yang ditentukan dengan rumus ketuntasan belajar secara klasikal, yaitu: siswa yang tuntas belajar dibagi jumlah siswa dikali 100 .

Kriteria ketuntasan hasil belajar siswa dapat dinyatakan sebagai berikut: (1) Ketuntasan individu apabila siswa telah mencapai KKM yang telah ditetapkan SDN PURI Mojokerto yaitu 71. (2) Ketuntasan klasikal apabila terdapat minimal $75 \%$ dari jumlah siswa dikelas yang telah mencapai ketuntasan hasil belajar.

\section{HASIL PENELITIAN DAN PEMBAHASAN}

Berdasarkanpenelitian yang telah dilakukan di SDN PURI Mojokerto , maka diperoleh hasil penelitian berupa hasil analisis butir soal pratindakan kelas dan tes formatif, data observasi tentang penerapan pembelajaran kooperatif tipe 
TPS (Think Pair Share) yang berupa pengamatan aktivitas siswa dan guru, serta data nilai pratindakan kelas dan tes formatif dari setiap siklus.Data hasil uji coba butir soal yang diperoleh berupa analisis validitas dan reliabilitas dari soal pratindakan kelas dan tes formatif setiapsiklus, sedangkan data hasilobservasi berupa hasil pengamatan penerapan pembelajaran kooperatif tipe TPS (Think Pair Share) yaitu pengamatan tentang aktivitas siswa dan aktivitas guru.

\section{Analisis Data Penelitian dan Pembahasan}

Tabel 4.3 Analisis Hasil Pra Tindakan KelasDistribusi Hasil Pra Tindakan Kelas

\begin{tabular}{|c|l|l|}
\hline No. & \multicolumn{1}{|c|}{ Uraian } & HasilPraTindakanKelas \\
\hline 1. & Nilai rata-rata pratindakankelas & 60,43 \\
2. & Jumlahsiswa yang tuntasbelajar & 6 \\
3. & Prosentaseketuntasanbelajarsecaraklasikal & $26,09 \%$ \\
\hline
\end{tabular}

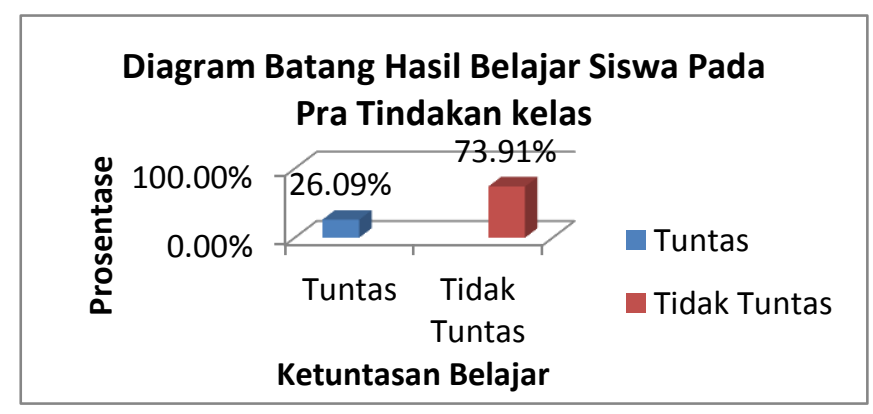

Gambar 4.1 ProsentaseKetuntasanBelajarPadaPra Tindakan Kelas

\section{Analisis Penelitian Pada Siklus I}

Tabel 4.4 Distribusi Hasil Test Formatif I

\begin{tabular}{|c|l|l|}
\hline No. & \multicolumn{1}{|c|}{ Uraian } & \multicolumn{1}{|c|}{ Hasil Test Formatif I } \\
\hline 1. & Nilai rata-rata testformatif 1 & 68,04 \\
2. & Jumlahsiswa yang tuntasbelajar & 12 \\
3. & Prosentaseketuntasanbelajarsecaraklasikal & $52,17 \%$ \\
\hline
\end{tabular}

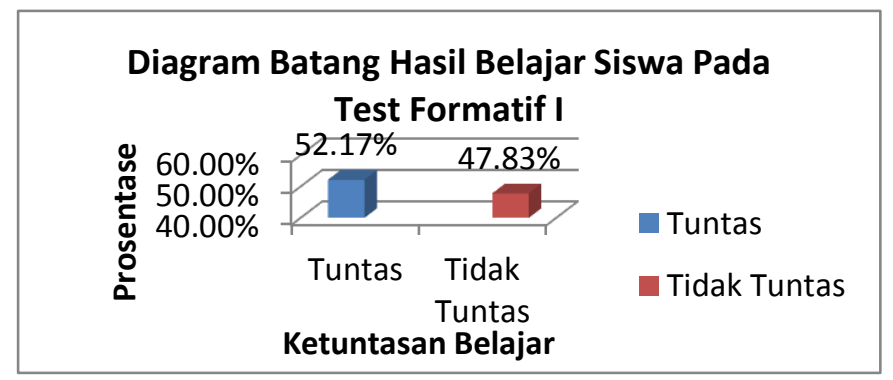

Gambar 4.2 Prosentase Ketuntasan Belajar Pada Test Formatif I Rata-rata aktivitas siswa pada siklus I adalah 8,087.

47 BRILIANT: Jurnal Riset dan Konseptual Volume 1 Nomor 1, November 2016 
Rata-rata aktivitas guru pada siklus I adalah 1,85.

\section{Analisis Penelitian Pada Siklus II}

Tabel 4.5 Distribusi Hasil Tes Formatif II

\begin{tabular}{|c|l|l|}
\hline No. & \multicolumn{1}{|c|}{ Uraian } & \multicolumn{1}{|c|}{ HasilTes Formatif II } \\
\hline 1. & Nilai rata-rata tesformatifII & 84,57 \\
2. & Jumlahsiswa yang & 17 \\
3. & $\begin{array}{l}\text { tuntasbelajar } \\
\text { Prosentaseketuntasanbelajar } \\
\text { secara klasikal }\end{array}$ & $73,91 \%$ \\
\hline
\end{tabular}

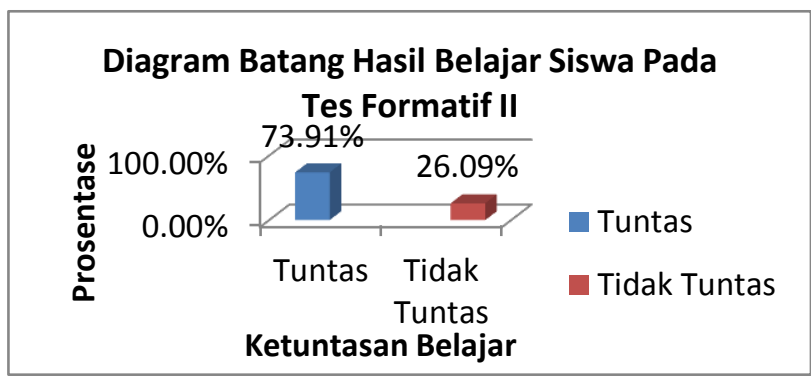

Gambar 4.3 Prosentase Ketuntasan Belajar Pada Test Formatif II

Rata-rata aktivitas siswa pada siklus II adalah 9,913.

Rata-rata aktivitas guru pada siklus II adalah 2,6.

\section{KESIMPULAN}

Berdasarkan hasil penelitian dan pembahasan yang telah diuraikan di atas, maka dapat disimpulkan sebagaiberikut: (1) Penerapan model pembelajaran kooperatif tipe TPS (Think Pair Share) dapat meningkatkan aktivitas guru kelas V SDN Puri Mojokerto pada materi sifat-sifat pengerjaan hitung pada bilangan bulat. (2) Penerapan model pembelajaran kooperatif tipe TPS (Think Pair Share) dapat meningkatkan aktivitas siswa kelas V SDN Puri Mojokerto pada materi sifat-sifat pengerjaan hitung pada bilangan bulat. (3) Penerapan model pembelajaran kooperatif tipe TPS (Think Pair Share) dapat meningkatkan hasil belajar siswa kelas V SDN Puri Mojokerto pada materi pokok sifat-sifat pengerjaan hitung pada bilangan bulat. Rata-rata hasil belajar siswa dengan penerapan model pembelajaran kooperatif tipe TPS (Think Pair Share)pada siklus I yaitu sebesar 68,04dengan ketuntasan klasikal 52,17\% rata-rata hasil belajar pada siklus II mengalami peningkatan dari siklus I yaitu sebesar 84,57 dengan ketuntasan klasikal 73,91\%.

\section{Saran}

Berdasarkan hasil penelitian dan hasil kesimpulan, peneliti ingin mengemukakan saran-saran yang berhubungan dengan peningkatan mutu 
pendidikan khususnya pendidikan matematika sebagai berikut: (1) Siswa hendaknya lebih serius dalam setiap mengikuti proses pembelajaran, sekaligus membiasakan dan mengembangkan kompetensi masing-masing sehingga hasil yang dicapai lebih memuaskan. (2) Guru hendaknya lebih selektif dalam memilih model pembelajaran yang akan digunakan untuk meningkatkan kualitas hasil belajar siswa. (3) Guru hendaknya lebih melibatkan siswa dalam proses belajar mengajar melalui belajar kelompok atau diskusi.

\section{DAFTAR PUSTAKA}

Arifin, Zaenal. 2010. Membangun Kompetensi Pedagogis Guru Matematika. Surabaya: Lentera Cendikia.

Arikunto, Suharsimi. 2006. Prosedur Penelitian Suatu Pendekatan Praktik (EdisiRevisi VI). Jakarta: RinekaCipta.

Arikunto, Suharsimi. 2010. Prosedur Penelitian Suatu Pendekatan Praktik. Jakarta: Rineka Cipta.

Ekawarna. 2011. Penelitian Tindakan Kelas.Jakarta: Gaung Persada Press.

Hudojo, Herman. 2001. Pengembangan Kurikulum dan Pembelajaran Matematika. Malang: Universitas Negeri Malang.

Iskandar. 2011. Penelitian Tindakan Kelas. Jakarta: Gaung Persada.

Mudjiono., \& Dimyati. 2009. Belajardan Pembelajaran. Jakarta: Rineka Cipta.

Murtadlo., \& Amiyah. 2011. Manajemen Pembelajaran Inovatif. Surabaya: Iranti Mitra Utama.

Ratumanan, Tanwey Gerson. 2002. Belajar dan Pembelajaran. Surabaya: Unesa University Press.

Sagala, Syaiful. 2009. Konsep dan Makna Pembelajaran untuk Membantu Memecahkan Problematika Belajar dan Mengajar. Bandung: Alfabeta.

Sudjana, Nana. 2011. Penelitian Hasil Proses Belajar Mengajar. Bandung: PT Remaja Rosdakarya.

Sumanto, dkk. 2008. Gemar Matematika 5 Untuk Kelas V SD/MI. Jakarta: Pusat Perbukuan Departemen Pendidikan Nasional.

49 BRILIANT: Jurnal Riset dan Konseptual

Volume 1 Nomor 1, November 2016 
Suprijono, Agus. 2009. Cooperative Learning Teoridan Aplikasi Paikem. Yogyakarta: PustakaPelajar.

Trianto. 2007. Model-Model Pembelajaran Inovatif Berorientasi Konstruktivistik. Jakarta: Prestasi Pustaka.

Trianto. 2011. Mendesain Model Pembelajaran Inovatif-Progresif, Jakarta: Prestasi Pustaka.

Undang-Undang Republik Indonesia Nomor 20 Tahun 2003 Tentang Sistem Pendidikan Nasional, 2003. Jakarta: Departemen Pendidikan Nasional. 